\title{
Evaluating the Philosophical Foundations of Development Theories
}

\author{
J. Chidozie Chukwuokolo \\ Department of Philosophy and Religion, Ebonyi State University, Abakaliki, Nigeria \\ Email: jerrychidozie@yahoo.com
}

Received August $4^{\text {th }}$, 2012; revised September $1^{\text {st }}$, 2012; accepted September $15^{\text {th }}, 2012$

\begin{abstract}
This paper in its contribution argues that there is the need to understand the metaphysical and epistemological issues that undergird human behaviour and ipso facto human nature in formulating development theories. This will enhance appropriate evaluation and application of these theories for the betterment of any society. It establishes the relevance of human nature to social theories. Accordingly, social theories spur the explanation, nature, function, institutions, and prediction of social patterns of development. Since society is primarily an amalgam of people in social intercourse, human nature impinges on human behaviour. Thus, just as the nature of molecular behaviour enhances the understanding of the behaviour of gases, proper understanding of social theories and those things that spur them enhance the understanding of human societies. Thus the understanding of the coherence and workability of any social theory is therefore predicated on the perspective gained on human nature. The critical, analytical and evaluative methods of philosophy will be dominant in the work.
\end{abstract}

Keywords: Philosophical Foundations; Development Theories and Human Nature

\section{Introduction}

What are those issues that plague the philosophical mind in formulating development theories? In other words, theories of societal development are supposed to fall under the purview of sociology and anthropology, what are the philosophical interests in such areas, can there be any justifications in philosophy studying development theories? It is obvious that philosophy has certain approaches that are sui generis into investigation of any subject matter; development theories inclusive. In other therefore to appreciate the formulation of the goals, objectivity and universality of development, certain considerations have to be made. What are those things that inform the formulation of development goals and objectives? Theories of society (whether good or bad) have implicit in them theories of human nature. In order to appreciate such theories, there is the need to evaluate the conceptions of human nature that undergird them. However, philosophers of various epochs and ideological leanings seem to attest to the view above. Leslie Stevenson avers that: "The meaning and purpose of human life, what we ought to do and what we can hope to achieve-all these are fundamentally affected by whatever we think is the real or true nature of man.” (Leslie Stevenson, 3).

On his own, Amerigo Lapati (1973: pp. 501-502) shares this perception when he asserts that, "Basic to the study and understanding of any theory that deals with human behaviour is the concept of the nature of man underlying that philosophy or theory". However, human nature is a product of biological, social, physical-chemical, psychological and religious elements that engender the uniqueness of human being. Development theories hinging on human nature therefore are predicated on certain metaphysical and epistemological commitments.

Two fundamental metaphysical commitments arise- one passive and the other autonomous. The passive one entails a me- chanical deterministic orientation that subjects man to the iron clad laws of nature namely environment and genetic inheritance. On this construal, the cosmos is governed by a web of natural laws; humans are part of this cosmos and ipso facto they are subject to these laws. This implies that there is no absolute wholly other that is incomprehensible to humans yet controls human affairs. Humans on their own are not reducible to any essence that can not be investigated scientifically such as the self. Thus every "essence" of man is investigable, manipulable and predictable. Martin Hollis (1977: p. 5) calls this typology of man "plastic man", as against "the autonomous man".

The autonomous conception of man is that, that confers on man elements of freedom, responsibility and choice. Freedom predisposes that any attempt to study man entirely as a lawgoverned being results in a ruse. All that can be done is to elicit justifications from acting agents as to why they act the way they do. Humans on this construal are free and rational to certain respect if not entirely. There is an essence which crystallizes in a unique self that makes choice from alternatives in any circumstance. Thus seen, autonomous conception places man the "rational subject self" on responsibility for his actions in contrast to the plastic man whom if we stretch things very well is absolvable from responsibility for his actions.

At this stage, it is note worthy that various theories exist under the above metaphysical conceptions of human nature. There are those who believe that man is a bio-geographically determined being. An example is Jared Diamond who opines that environmental determinism resulting from bio-geography accounts for the differences that exist among societies in development. There are others as B. F. Skinner who postulates psychological determinism where social phenomena are reduced to psychology.

It is pertinent to establish the relevance of human nature to social theories. The basic assumptions of social theories are to 
postulate the organization of society, its functions, structures, institutions, nature and patterns of development. Society primarily is an amalgam of people in social intercourse. Human nature on its own impinges on human behaviour. Just as the nature of molecular behavour enhances the understanding of the behaviour of gases, the understanding of human nature enhances the understanding of human societies. Our understanding of the coherence of any social theory therefore is predicated on the perspective gained on human nature. It is on this paradigm that we can appreciate Hegel's postulation of absolute monarchy or Locke's representative democracy.

J. C. A. Agbakoba (2001) notes three ways in which theories of human nature enhance our understanding of social theories. He starts by positing a teleological conception where the purpose of society and the way it is organized and structured are seen as means of reaching some goals that are inherent in man and which man naturally strives to attain. For instance, the social contract theory of Jean Jacque Rousseau could be predicated on a perceived principle of equality at birth which societies have lost in their evolution. The need for re-organization of societies to reflect this equality stares them in the face as successes are judged in terms of their degrees of equality.

Causality devoid of teleology is the second way. Social structures and institutions are perceived as determined by human nature through a causal web. This presupposes that societies have no goals except those their members chose. Thus, nature does not provide inherent ends. The third way is that of human free will. For instance man always does what he freely wills; the regularities of action in the society are mere coincidences. This results from the capability of individuals having various means of actualizing the same thing. All we can do therefore is advisory roles in man. This is the view of any thorough-going existentialist (J. C. A. Agbakoba, 2003: p. 5). We shall note the inescapability of determinism in any study of human nature and development theories as the major conceptions result from disagreement and reconciliation of the application of determinism to human behaviours.

On the epistemological commitment what people hold as the truth influence their path to development. The epistemic outlook of a people which is the predominant truth or knowledge acquisition process at the disposal of such a people determines the rate and pattern of development of such society. Our contention is that the epistemic world view of a people colour the kind of knowledge available in the society and hence the path of development pursued by such a society. This is evident in the culture-thesis of development held by GWF Hegel where both his epistemic and metaphysical standpoint influenced his development theory.

From the fore-going it is evident that the metaphysical and epistemic outlooks of societies are fundamental to the perception of human nature which underpins development theories. In this regards, we shall critically pursue the philosophical foundation of development under the following sub-headings:

Determinism, freewill and development; Teleology, causation and development; Materialist interpretation of development.

It is obvious that there are other areas of bisection between philosophy and development; we shall suffice with the above sub-headings especially as we have carried out comprehensive research elsewhere bordering on the topic.

\section{Determinism, Freewill and Development}

Determinism is a principle that favours that all events have general laws in which they are interconnected with other phenomena such that understanding these laws confers on the researcher the capacity for prediction. It is believed that science as it is constituted embodies sets of equations that are in such interconnected link-state of matter in time. In classical Newtonian physics, these states are identified with the positions and momentum of particles. Thermodynamics identified these states with pressure, volume, temperature, free energy and entropy. Recent results of quantum physics have identified the state with the PSI function or probability state. This probability state does not imply imperfection in knowledge but all that is knowable at the time. This has made some philosophers to conceive determinism as having the stamp of necessity and impossibility as complementary. This enthrones the law of excluded middle: anything that happens in this law governed universe must happen and vice versa, no middle way. Bernard Berofsky (cited in Agbakoba, 2001: p. 7) brings out clearly this law-like nature of determinism when he avers that it is a position that, "all events (facts, states) are lawful in the sense roughly that for any event, e, there is a distinct event, d, plus a (causal) law which asserts whenever $\mathrm{d}$ then $\mathrm{e}$ ".

This brings out clearly that no event escapes a set of sufficient conditions for its occurrence. It is pertinent at this stage to point out that this link between two events is not accidental but is of necessity. If this is taken, the thorough going determinists do assert that all the investigation of nature must go on adinfinitum in the search for causal antecedents without any area that determinism does not transcend. Determinism reviewed on this construal conflicts with the concept of the person as a unique entity that transcends deterministic analysis and one with freewill and responsibility. However, Hollis argues against the self as a unique entity not subject-able to law. Accordingly, he asserts that one cannot be distinctly unique as an individual; but one can only be unique in so far as such a one "is the only instance of the intersection of a complex of laws" (Hollis, 1977: p. 11). Thus seen, free will and ipso facto free action is a ruse especially when construed as an act that proceeds from an uncaused unique personality capable of making choices given several alternatives.

Apart from this, it is evident from modern physics that the elements/particles that compose the world are not things but conceptual waves of probability. This probabilistic stance extends to human actions and confers limitations to it. Thus, determinism must reflect the limitations of man in its theorizations. For instance, there are instances of "chance events" in real life as when luck plays out but determinism denies such objective chance. But these "chance events" could be linked by laws with previous events. In this regard they may not be infractions of determinism. This brings to fore the view of Sander Pierce who rejects universal or thorough determinism. For him, this rejection is anchored in tychism which is an element of spontaneity in the world. But, the study of the world is aimed at conferring on the investigator the ability to predict events. Determinism when presented in the above sense removes predictability from the study of the universe. This is because a system or an event could be deterministic without being known. This means that those sufficient conditions or laws governing such events may not be known and the prediction of such events may not be due with certainty.

It is noteworthy to observe that determinism though not established conclusively empirically is much too valuable to abandon. This is because like induction, it is not so much meta- 
physical as methodological as it describes a feature of human struggles rather than the world. Contrarily, determinism is not thoroughly refuted empirically. This results from the fact that failure to establish sufficient conditions of say an event does not negate the existence of such conditions. All it establishes is the incompleteness and incorrectness of human analysis of the events. Hence, determinism is not an empirical truth defendable as a correct description of the world. Ernest Nagel (1996: p. 354) sees it as possessing the status of a "guiding principle" which formulates in a comprehensive fashion one of the major objectives of positive sciences. In supporting Nagel, Agbakoba has this to say: In addition, we do have some good reasons to agree with the thorough determinist: every advance in science and technology confirms or enhances the plausibility of determinism; and in our everyday interaction with fellow human beings, we do ensure the operation of causality and law-like regularities... We thus generally presume that choices and decisions don't just happen, but have causes and effects and are thus determined (8-9).

But is determinism the same with fatalism? We usually hear such assertions as whatever will be, will be no matter whatever we do. Fatalism carries in it a negation of freewill and it is in this way that it differs with determinism. Determinism has not conclusively negated freewill but fatalism assumes such a posture. But before we explore this further, what is fatalism? This is a negation of the import of freewill in the affairs of man to the extent that events are pre-ordained with certainty that they must occur whether we like it or not. As Reuben Abel (1976) puts it:

Fatalism asserts not that every event has a cause, but that every event has been pre-ordained; that the causes of events are outside ourselves; that whatever occurs does so regardless of what we do; that we cannot act, since events are beyond our control; that there are no alternatives; that deliberation is illusory. (243)

It is a vacuous doctrine in which its irrefutability is built on an untenable law of excluded middle for everything points to its establishment. This irrefutable stance is typical of fatalism. As Abel (1976) puts this difference between fatalism and determinism:

The irrefutability of fatalism is built into it, like the self-proclaimed infallibility of a sacred writing. If you point this out, the fatalist says your argument, too, is preordained. Determinism likewise can be neither proved nor disproved; but determinism is not for action. Its efficiency is pragmatic: it is the refusal to abandon the search for causes. (243)

However, fatalism is not flawless: this results from its erroneous assumption that the future is mapped out in such a way that the "self" or the "will" has no impact in constituting it. But, it is evident that man's freewill has been exerted in the past in such a way that predictions are refuted. This is typical of the Cassandra paradox: a prediction to you about you may motivate you to defy the prediction. Nevertheless, we cannot know whether fatalism is true or false. Even when it is true, it is not valuable to us as it ought not to be a guiding principle for anybody. Even a fatalist does certain things for himself, for one who has a fatalistic prophecy that such a one would become a professor must and often do work hard to realize such lofty ambition. We shall therefore, jettison fatalism and go ahead to see whether determinism can serve as a guiding principle in formulating development theories.

Determinism as postulated above has to grapple with one of the perennial philosophical problems of freedom, choice and responsibility. Is man actually free? And if not is he responsible for his actions? Abel (1976: p. 243) observes that "this is an important problem because freewill lies at the intersection of two fundamental but perhaps incompatible convictions: the subjective or inward phenomenological certainty of freedom: and determineism, the insistence that every event has a cause". Further, we can still ask whether freewill conflicts with determinism. Philosophers of different epochs have attempted to find solutions to the above questions raised. One such attempt results in reconcilliationism. According to this view, determinism properly describes non-behavioural reality; however freedom still exists at the behavioural sphere. J. I. Omoregbe (2004) seems to share this view. According to him, Hume's assertion that motives are the determining necessary factors that condition human behaviour is a ruse. This is because man freely chooses from motives that present themselves as alternatives. As he puts it:

Hume has a peculiar understanding of freedom and free actions. He argues that if we say that an action is free, we thereby mean that it has no cause, and that it is simply the product of chance. But motives do not determine actions; they only influence them, their influence is only, in-so-far as they are allowed by human freedom. Man is free to accept or reject any particular motive; he can refuse to yield to the influence of any particular motive. Among many motives that may present themselves for action, man freely chooses which of them to accept and which to reject and suppress. Motives therefore do not eliminate freedom as Hume thinks. (Omeregbe, 41)

Reconciliationists are all agreed that freedom occurs when an agent is not constrained by force from doing what he wills or forced to do what he wills not. Thus, what is imperative to establishing whether an agent is free or not, is the understanding of the laws that govern any action. Such imperatives capable of obstructing an action as external force, pathological state of the mind, insanity etc are termed excuse factors by Francis Raab capable of inducing us to withdraw responsibility from the agent. On this construal, the self is asserted as autonomous and capable of taking decisions without yielding to external factors. This is typical of circumstances where in the medieval inquisition era, convinced men refused to recant their positions even when death stared them in the face.

Agbakoba has argued against libertarianism as postulated by Berlin according to which the fear of the disappearance of our moral language establishes determinism. According to him, Berlin begged the question in his fear of the disappearance of our moral language as he needed to establish that we shall never succeed if we tried to alter our actions. As he puts it:

In addition, for our moral language to disappear as Berlin feared, we not only need to accept determinism, but also that every cause of an act is an evidence against the imputation of responsibility. This is however not the case; Berlin merely begged the question. He needed to show that if we tried to alter our actions we shall never succeed (11-12).

Although the establishment of a free self that is not susceptible to determinism is difficult, the doctrine of emergentism has been used to ground this view. Emergentism is the view that evolution has established an added feature that is irreducible to its components. This irreducible component enables us to assert that it is man himself not a part of him that performs or causes his actions. This irreducible property is not an assemblage of political phenomena that are acting in tandem with natural laws. 
However, this view masquerades a discussion on consciousness which we accept its inexplicable stance. Richard Taylor's (1963: pp. 61-62) attempt at dismissing such metaphysical entity is paradigmatic here:

...the complexity and apparent inexplicability of human behaviour is now reason for us to seek the understanding of man in a metaphysical realm radically different from that used in the understanding of other things both organic and inorganic.

Although the establishment of a subject self that transcends determinism is beyond our scope in this work, all we have to say is that it has not been dislodged. Otherwise how can we account for memory in man?

At this juncture, it is pertinent that we sum that the opposition between determinism and freedom and its attendant unsuccessful attempts at reconciling them exist at a fundamental metaphysical level that begs for conclusive results so far. At the core of the problems is what human beings think themselves to be; if determinism were true, man's concepts of morality, law, efforts of the will crashes. Yet these concepts are integral in our day to day decisions. The problem is made more acute as its adherents are made up of materialists or naturalists who deny the existence of the self capable of acting freely. Idealists and or dualists while believing in the existence of a free self can limit their acceptance of determinism to the world of matter. However, as noted earlier the establishment of a free self capable of exerting freedom as we know it is difficult. It is worse off when the interaction between mind and matter are attempted. We shall assert that believing or jettisoning either determinism or freewill is reductive and does not capture reality as it is. This is because we perceive actually elements of the two. Freedom does not necessarily contradict determinism. Therefore, it is most plausible to acquiesce to the version of reconciliation that blends the two. This augurs well with the synthesis inherent in the dialectical process where determinism is thesis and freewill the anti-thesis.

Development theories have carried in them these metaphysical commitments that have hampered their proper explanations on the development differences that exist among societies. Environmental determinism for instance, has committed its adherents to the dangerous position of those who are disadvantaged by such environments to give up hope in attempting to change their circumstances. But commitments to either determinism or freewill have influenced to a greater deal how people have reacted to their development levels via theorizations. But development (event-determined) cannot be described adequately, except contextual knowledge is added to it.

\section{Teleology, Causation and Development}

When explanations to the development of an organism or organization are sought in terms of purpose, and or goal states, a teleological explanation is sought. There are two kinds of goals elicited by this sort of explanation: goal intended and goal directed. A goal intended behaviour is one in which an agent consciously sets out goals or ends and extends stimuli geared towards the actualization of such ends or goals. A goal directed behaviour is integral to the nature of the agent involved and cannot be imputed intentionality and consciousness of activity, but whose activities can still be purposive. For instance, an acorn could be said to be geared towards the end state of becoming an oak. But what is teleology? Alan Ryan (1975: p. 184) defines it thus:
To explain an event teleologically is to explain its occurrence on the grounds, that it is contributory to a goal or end state, and to imply one essential thing - that the goal or end state is sought or maintained by the system in which the events take place. What this requirement amounts to is that the system in question has to possess some kind of negative feedback characteristic in the sense that the movement away from its goal is compensated for by some kind of corrective mechanism.

Certain philosophical issues arise with teleological explanation constructed in this way: Firstly, there is an apparent fallacy revolving around any causal explanation presented as if effect precedes cause. This concerns the typification of relationship between the determining and determined factors within this explanatory paradigm. Goal intended behaviour is easily amenable to this mould of causal explanation while it is more tenuous to subject goal directed behaviour to such reductive category. Some philosophers have as Richard Braithwaite (1968) opined that goal directed behaviours could be reduced to goal intended ones by attributing drives, instincts or conatus to the organism. This is because in lower organism, these attributes are regarded as consciousness in debased forms. This means that the consciousness in man differ from those organisms in degrees not in kinds or forms. Hence, human beings streamline their goals very clearly more than animals. Though instincts may be regarded as fundamentally different from consciousness, it functions as consciousness in any goal intended behaviour.

This view is however susceptible to the criticism of introducing a metaphysical entity whose only property is being the cause of goal-directed behaviour. This stems from its unverifiability status hinged on unconditionality. Its existence can never be established in alio of the covert behaviour it is supposed to explain.

Again, scientific progress has imputed causal explanations to certain goal-directed behaviour. This is done when such behaviours are explained in terms of their physico-chemical properties. However, this reductive tendency of subjecting goal-directed behaviours to ordinary causal relations have made some philosophers as Ernest Nagel and Carl Hempel to discard teleological explanations as misleading ways of stating causal explanations. For instance, Nagel's argument that " $X$ occurs in order that $\mathrm{Y}$ " taken as $\mathrm{X}$ is the sufficient condition for $\mathrm{Y}$ is a misleading way of presenting $X$ as the cause of $Y$. Alan Ryan (1975: p. 185) has noted correctly that this causal flow is wrong: the intention of the argument is to explain the occurrence of $\mathrm{X}$ by $\mathrm{Y}$ and not vice versa. According to him, when $\mathrm{X}$ is made the sufficient condition for $\mathrm{Y}$, it implies that any change in $\mathrm{X}$ should cause a change in $\mathrm{Y}$; but where it is stated that $\mathrm{X}$ occurs in order that $\mathrm{Y}$, it implies the reverse.

Further, critical observation will lay bare another flaw in such explanation for teleological explanations do not state the obvious attainment of the goal. For instance, that $\mathrm{X}$ is the sufficient condition for $\mathrm{Y}$ denotes that the occurrence of $\mathrm{X}$ automatically makes $\mathrm{Y}$ manifest. But expressing it as $\mathrm{X}$ occurs in order for $\mathrm{Y}$ does not carry the automatic import that $\mathrm{Y}$ must occur whenever $\mathrm{X}$ is seen. Lack of the goal attainment does not remove the teleological import of the expression, after all the essence of the expression is to explain the occurrence of $X$ via the end state $\mathrm{Y}$ and not the occurrence of $\mathrm{Y}$.

All we have done so far is to explicate the fact that teleological explanations are hardly reducible to ordinary causal explanations. The explanation of the event $\mathrm{X}$ results because it 
plays a cardinal role in the attainment of the goal Y. Even though that the end-state usually manifest after all the contributory composite events are available, yet it is this end state that adduces explanation to them. This is because to actualize the goal in mind, certain relations are prior established before the goal.

From the foregoing discussions, it seems that teleological explanations are established by induction. Goals and states of affairs that lead to them are identifiable as the relationship existing between goals and their contributory factors is such that the later is a necessary condition for the former. It is pertinent to note that this does not exclude the contributory roles that alternative factors play. But that induction enables us to observe the various conditions and alternatives that enhance the progress of a system's attainment of its goals; this maps out the paths to the systems persistence towards progress. As Richard Kitchener (1983: p. 798) puts it:

It is the establishment of teleology by induction that necessitates a holistic approach in teleological explanations. There is a need to view teleological relations in its entirety, not only as $a$ whole but as one with internally related parts. It is in this way that one is able to identify the goal state and the elements that contribute towards bringing it about.

Another issue that is worthy of observation is the fact that though non-teleological explanations are numerous, they are never mentioned in the teleological explanations. Rather, these factors are subsumed under the phrase "under normal development conditions”. It is taken for granted that development must progress normally hence no attempts are made to specify teleological explanations as stipulating conditions under which development must occur. Again, discussions on the duration of successive stages of the contributory factors are glossed over or ignored completely. This is made more manifest by the unspecific nature of teleological explanations. However, no matter the extent of weaknesses of the teleological explanatory model, proper observation, calculation and causal analysis, can provide us adequate knowledge of how successive stages of development occur. Hence, causal explanation plays a fundamental role in explicating the essence of any system under study. Ryan observes on this note that: "Everything I have said so far about our inclination to look for hidden mechanisms and to inquire into the working of systems suggest that teleological explanations are very much our first thought, not our last.” (Ryan, 1975: p. 186).

At this juncture, let us examine causality in se. The concept of causation has passed through many phases; Aristotle speaks of causation in terms of his four causes; formal, material, efficient and final. However, his notion of cause has been more accurately designated as aspects of being for they hardly precede what they are causes of. For Francis Bacon, cause is designated as means to an end. Since, this end is the manipulation of nature, knowledge of causes became synonymous with power. Gottlieb Leibniz conceives cause in terms of sufficient reasons while Rene Descartes sees cause as ground, necessity or implication. David Hume however had impacted greatest on the concept of causation when he hit at its greatest problem; being able to establish the observation of external event compelling another to happen by necessity.

What then is causality? This entails the relation between two events: phenomena or things in which one event occurs before the other. While the first is said to be the cause, the latter is said to be the effect. As Agbakoba (20) puts it; "A causal statement generally takes the form of event A causing event B, which is an effect it produces."

However, a critical analysis of the various ways we conceive causation will expose its problematic: how to characterize the relationship between the two events. For instance, it was believed that lightening causes thunder because lightening precedes thunder. But, it is known now that both lightening and thunder are two aspects of the same thing, that is, electrical discharge in the ionosphere. The discharge simultaneously emits sound and light. The implication of this is that for A to cause $\mathrm{B}$, there must be $\mathrm{C}$ (physical contact). But Abel avers that the moon and the sun cause the tidal waves of the sea from a remote distance. Same is true of the causal influences brought about by the remote control of the electronic gadgets. It was also thought that a cause must precede its effect, but breakthroughs in quantum physics (relativity theory) have disproved this. Even in logic the necessity that causation carries is jettisoned for material implication of modern extensional or truth functional logic.

Be these as they may, positivists attempt to characterize causality as carrying the stamp of necessity and sufficient condition for the occurrence of events. They hardly establish this necessity of relation between two events. This view is similar to Hume's constant conjunction theory of causation. This implies that causal laws express necessity and sufficient condition that make events occur. Positivists also hold that the two events should not imply each other.

Abel notes the problematic of holding causality on the above light. According to him, when events are analyzed, they often turn out to be less discrete than we would wish in deciding what causes what. In effect, it means that it is difficult in the legion of possible causes to anchor the actual cause of event. He cites Brand Blanshard's example of malaria. For him, it is difficult to locate the actual cause of malaria from the legion of alternative causes namely: the bite of anopheles mosquitoes, the actual depositing of plasmodia, the attack of the red blood cell by the plasmodia, the loss of hemoglobin, the deprivation of oxygen in the tissues of the body. He concludes that all we do in sorting out causes and effects is to impose an intelligence structure of discrete events upon the continuous stream of occurrences to suit our purpose because it is difficult to locate the cause of malaria. (Abel, 12-13)

Positivists' success however is in noticing the differences between accidental generalizations, that enumerate and cannot license counterfactual statements, and causal statement that are nomothetic capable of licensing counterfactual statements. They do not make distinctions between mere regularities and defacto regularities. As Agbakoba puts it:

However, they are still unable to make a distinction between defacto and mere regularities such as the succession of day and night, and causal laws or statements. Defacto regularities do not tell us why a thing happens; only that it always occurs. For instance, the regular sequence of day and night tells us only that the one follows the other, and not why it does so. But causal laws are meant to tell us why a thing or an event occurred the way it did. (Agbakoba, 2003: p. 21)

Realists on their part hold that necessity exists in nature as the observed regularity of events are indicative of a generative operating substratum. For them, there is the need to unmark the phenomena for the underlying mechanism at work. Hence, contrary to the belief of the positivists, they do not assert the logical dependence of events. This follows from the fact that 
realists believe that micro entities as the sub-atomic particles underlie macro entities as the desks we observe. Hence, macro and micro entities are logically dependent on each other's properties and relations. We shall sum up by asserting that though it is difficult to characterize the relation between cause and effect, the realist view is preferable. This results from the difficulty of the positivists in establishing the basis of scientific laws and also on our convincing assumption that there is necessity in nature.

What are the impacts of our discussions on teleological explanation, and causation to development? We shall start by asserting that the feedback mechanism in the theories confers plasticity to the theories. And this has a far reaching effect on development conceptions. This is explicated in the persistent capacity of systems in the attainment of set goals given varying conditions via multiple alternatives of activities. This is impacted upon by the favourable socio-psychological stance of humans explainable causally and teleologically that goes paripasu with the notion that the meaning of a thing motivates an action. The important aspect of this is that though plasticity is inherent in the theories, they do not eschew choice. This is because if we assert that human beings act in tandem with laws and necessities, we shall not run into contradictions as they could either accept or reject such laws. Our contention in this work is that it is the rational application of choice by varying peoples of the world that makes for the differences that exist at the levels of the development of peoples. This follows from our view that plasticity does not abrogate choice and choice is made by how adaptable a people's rationality is to their existential needs. The implication of this is that the consistency, coherence and workability of any social theory are predicated on the perspective gained on human nature.

\section{Materialism and Development}

The developmental stance of any group of people is a product of their perception of the ultimate reality. Any people that see the ultimate reality in terms of idea will over-emphasize aspects of the society that promote idealism. So also is any society that lay much emphasis on matter as the ultimate reality. Such a society will tend to develop material aspects of society at the expense of the other dimensions of reality. We shall in this section, address the following questions: what is materialism? How does materialism affect the course of socio-economic evolution of society? Does this externalistic disposition cater for mankind's holistic developmental needs? We shall round off this section by creating an internalist-externalist dimension of materialism in order to show how this is the most consistent aspect of materialistic theory that has gained most perspective on human nature as it really is.

One of the basic questions of philosophy is ascertaining the interrelationship between thinking and being, spirit or nature which is primary? Materialism is an attempt at grappling with this question. To this extent, materialists, posit the understanding that the world (reality as a whole), the sun, the moon, the whole earth, animal and man have independent existence independent of human consciousness, and that the human being on his own is a product of the world wherefore he appeared and wherein he lives. The materialist's answer to the basic question above does not limit itself to asserting that matter is primary to consciousness, but also offers a stand point on what matter is? This implies a definition of what is to be considered material and spiritual, a study of their essences and a justification of the materialist idea of the relationship between consciousness and being and of spiritual to material.

The idea of materialism therefore could be summed as arising from the notion or idea that matter is the essence of reality, and that matter creates mind and never vice versa. This implies that the mind and all its qualities (thought and thought processes) are bye-products of the brain; brain itself and its qualities arose at certain stage in the evolution of living matters. Hence, the brain and its qualities are products of the material world. It is pertinent at this stage to note that in the historical development of materialism, two basic stances to the understanding of matter are observed. As F. M. Burlatsky et al. (1985) put it:

An understanding of matter is the basic element of a materialist philosophy... In the process of historical development of philosophical thought, two basic approaches to the explanation of matter emerged. In approximate terms, they could be described as: 1) The explanation of matter from the standpoint of its structure, and 2) The explanation of matter in terms of solution of the basic questions of philosophy. Both approaches always existed in one variation or another; the former however, was popular in the earlier period of the development of philosophy... Under those circumstances, philosophy concentrated on explaining the essence of matter, its relation to consciousness, on ascertaining what its attributes are. (51-52)

Throughout the early history of philosophical materialism, materialist philosophy was enormously successful in the elaboration of theories of matter and in its struggle against idealism, agnosticism and obscurantism from antiquity to the early 19th century. Some philosophers believed that it offered a convincing justification of the objective nature of matter and of its knowability. Also standing in tandem with the level of scientific knowledge, it explicated a theoretical position on the structure of matter, on the relationship between matter and motion, and made demonstrable the objective nature of space and time.

Materialist theory, however, showed some shortcomings as social production, science and world philosophical thoughts developed enormously in the mid-19th century. It became obvious that matter was not being studied systematically. Again, the most serious defect to the study of matter at this period was its metaphysical understanding: more often than not, matter, motion, space, time and other aspects of matter were seen in terms of isolated and independent concepts that independently foundate the universe. There was hardly any scientific approach to the unity of matter and motion. In effect, a mechanism where the motion of matter and all changes in nature were presented as varieties of mechanical movement was obviously a shortcoming. Another shortcoming was that since matter is understandable in terms of the ultimate reality, it was not extended to social life. This resulted from the restricted identification of matter with nature; hence there was hardly any discourse on matter as the foundation of the social history of mankind.

These shortcomings and N. G. Chernyshevsky's (1950: p. $675)$ view that "matter is what exists. Matter possesses qualities. Forces are manifestations of qualities. What we call natural laws are modes of operations of the forces” laid a foundation for Marxist scholars to explore the historical-social dimension of the development of matter. It took Karl Marx, Fredrick Engels and Vladimir Ilyich Lenin (1975) to effect this revolution on matter and extended it to all other spheres of philosophy. F. M. Burlatsky et al. (Eds.) put it this way: 
The most important contribution by the founders of Marxism to the elaboration of a qualitatively new understanding of matter lies in their discovery of the material foundation of social life. Pre-Marxian philosophy in its entirely (sic) both materialism and idealism, approached the analysis of historical social processes from idealist positions. Philosophy preceding Marx thought that social transformations took place under the impact of the will, intention and interests of men, mostly influential persons like Kings, emperors, generals, or educationists, writers and philosophers. They regarded society as the sum total of individuals, and as a being whose determining characteristic is thinking. (64)

This view point on the scientific explanation of matter vis-àvis socio-historical development of society was culminated in Marxian historical materialism and dialectical materialism. Marx's analysis of matter in the historical process revealed the underlying basis of the formation of all human qualities: labour. Accordingly labour is perceived as the material process of transformation of the natural environment by man. However, the issues remain whether labour is necessarily material. Burlatsky et al. (Eds.) see the import of labour thus:

It is not only the nature around man that is modified in the process of labour; one also changes oneself, ones own nature. Man improves his abilities and knowledge, develops his intellect for the performance of labour, man creates and uses work implements which he constantly develops and improves to make the labour more effective. Rather than take place in isolation, labour activity is performed by large groups of people and objective inter-relationship are formed between them required for the purposes of improving the productivity of labour. (64)

From the above, Marx discovered the underlying objective process of all social lives namely labour, social production activities, development of labour implement, relations between men in the process of labour, their development, and the development of man himself. A very significant dimension of this view is that desires, interests, thoughts and all spiritual lives are determined by matter in the process of social life. As Marx and Engels (361) put it: "The phantoms formed in the brains of man are necessarily, sublimates of their material life-process, which is empirically verifiable and bound to material premises." This significant discovery of the change of philosophical understanding of matter besides nature to include the foundations of social life entails a widening and expansion of the concept of matter. V. I. Lenin (1975: p. 6) captures this import when he avers that Marx had noted significantly "the consistent continuation and extension of materialism into the domain of social phenomena."

We have traced the evolution of the concept of materialism to Marx's ingenious discovery of matter as an integral part of the social process. This now elevates the concept of matter to history as the materialistic application of dialectics and materialism to history and social problems. What appears obvious is that in order to actualize one's labour finesse a certain kind of productive relationship emerges. This Marx explains in terms of economic materialism. According to this view, economic materialists assert that the totality of social progress including changes in the superstructure of any society results from economic or productive relationship that exists therein. Thus seen, a materialist inclination to development apart from being reductive will eschew the development of any dimension of society that is not materialist. This is typical of most Western (Eurasia) countries where emphasis are placed on the satisfac- tion of the material needs of man at the expense of his spiritual needs. So many spiritual decadences have been noted in this direction: sex-change, gene cloning. Really, man is a composite being; he has apart from his material dimension, a spiritual one as well. Any theory that limits its description of man to matter is not all-encompassing of man's true nature. Asian Tigeran development is hardly materialistic; it seems it is as a result of their spiritual values.

Be this as it may, Antonio Labriola's distinction between economic materialism and other kinds of materialism dealt an insidious blow on materialism. Thorold Rogers, a vociferous advocate of economic materialism had defined it as those materialists who ascribe predominant importance to the economic factors of life. Accordingly, they assert that economic factors predominate over-ridingly in social life and are the fruits of human knowledge and ideas. But, the way the idea of economic materialism is presented seems not to exclude historical idealism. Marxian historical and dialectical materialism may not necessarily preclude historical idealism since human knowledge and ideas could result to the kind of relationships individuals engage in materially in the course of their relationship with people in the process of production, that is, it is a variety of idealism.

So many factors other than economics influence the historico-social evolution of the society. These factors are subject to reciprocal action: each influences the rest and is in its turn influenced by the rest. The rise, development and fall of all social relations of any particular civilization are determined by the courses of its intellectual development, which in its turn, is determined by the attributes of human nature. The modern materialists teach that economic systems are conformable to human nature (social economic systems being the result of one or another degree of volume to human nature). Conversely, any economy begins to contradict the demands of human nature as soon as it comes into contradiction with the state of the productive forces. However, it is evident that the economic factor is subordinate to another "factor". This being the case, how can we call economic factors predominant?

Further, the materialist view of history falls into another pitfall. This is because it fails to offer true objective laws as it asserts in error that social development is material development, which is the same as development in nature. Social development can be brought about by a combination (give and take action) of will (spirit) and matter. This is because between the two, the factor which acts as subject is will (spirit). Therefore, they should have discovered objective laws from the aspect of spirit. But, on the contrary, they tried to discover objective laws only from the aspects of matter which is the object. Since, matter (object) is under the control of spirit (subject), certain laws can be found in matter. However, materialists use dialectical laws which are subjective to camouflage their interpretation as if these were based upon objective material laws.

If there are objective laws which operate on spirits, what are they? They are the laws of God's providence namely the laws of creation and the laws of restoration which have operated through man's will. These laws are not subjective but objective laws as they are determined by God and cannot be changed by man's will; man can hardly change these natural laws. At, this juncture two interrelated philosophical problems arise: they border on the issues of God's existence and the existence of mind and its interaction with matter. These issues culminate into the question of mind and matter which one is prior to the 
other? It is obvious that our tune seems to favour mind. This results from findings of modern science, that is, as it concerns the uncertainty theory. Classical physics had postulated mechanism and determinism at the micro and macro-levels of reality. But the results of modern physics have introduced non locality or immateriality of quantum reality.

This results from the randomness of the particles and the Heisenberg's uncertainty theory. Agbakoba (2001: p. 66) captures this lucidly:

The randomness of the particles depicts the fact that quantum particles behave with a certain randomness with result that we can only get probabilities at the micro level, physical laws at this level give only probabilities, though at the macro-level these probabilities coalesce to give near certainties.

The import of the above view is that particles at the micro-level introduce elements of non-locality to matter. This results from the faster-than-light sub-atomic particles that extension does not apply to, as underlying all realities. This is accountable for the non-relevance of the spatial separation of photons in measuring their co-relation. It is evident that quantum mechanics has obliterated spatiality and extension that are cardinal properties of matter. This results from the fact that no matter how distantly separated or extended, the measurement of particle as a light photon, automatically affects the others in the whole quantum reality. D. Hodgson (1991: p. 369) avers that in "quantum mechanics all systems which have interacted have correlations so that generally the whole universe will be a system as to which there can be simultaneity of distant events." Agbakoba (Mind, 67) again captures the import of the-faster than-lightentity thus:

But in physics no particle, i.e., nothing with mass (extendedness), can be faster than light, because for one, it would require energy approaching infinity to produce such a thing. Yet, this thing, which obviously is not a particle, is faster than light. Because it is faster than light it could traverse the whole quantum universe instantaneously making space like distances or motives irrelevant when we are considering it. By so doing, it more or less confers the relevance of our notions of space to an order different from itself, namely to the macro-world.

As we have seen, quantum mechanics establishes that at the sub-atomic micro-level of every reality is an underlying nonlocale and immaterial coordinating reality. Hodgson (1991: p. 385) picks up from this point to argue that it is this faster-than light reality that makes possible consciousness and mental events.

If at the base of reality especially the material reality is a subatomic micro-level, faster than light and non-locale, it follows that ultimate reality is non locale, without extension. Minds strongest property is non-locality; therefore ultimate reality is immaterial in the final analysis. We can therefore conclude from the above, that materialism does not necessarily exclude idealism. This is because contrary to the claims of materialists that material environment determines social consciousness; matter itself is an aspect of consciousness. Therefore, if we must separate matter and mind on this note, we shall hold that their imports are of mutual influence on man in the process of his historical evolution. That is to say that man's well-being is a con-course of mutual interference of both mind and matter.

Materialism as an externalist thesis for development by asserting that social progress is a handmaid of material productive forces is hardly all encompassing of all the forces of progress in society. This results from the nature and mode of the presenta- tion of the materialist argument as unable to account for the cause of the development of the productive forces itself. This is sequel to the view that dialectical development is brought about by struggle between contradictory elements within the productive forces. Materialist as Marx had asserted that development of the productive forces is self caused and they remain unable to make clear the content of the contradictory elements within the productive forces. Of course, this only asserts that development of the productive forces does not come about through the dialectic process. The idea and reason the productive forces develop continuously is obscure in materialist thesis of development.

The above observations bring to fore that emphasizing aspects of man's nature vis-à-vis development shall not give us what objectively exists in real order. This is because the evolution of the productive forces are not simply materialistic but a combination of internal (spiritual) and external (material) factors. Any of the factors should not be over emphasized at the expense of the other. Development is brought about by appropriate combination of these aspects, hence, the externalist externalist dimensions of materialism.

\section{Conclusion: The Role of Philosophy in Understanding the Dimensions of Human Nature in Development Theories}

It is pertinent that in concluding this work, we should touch the epistemic commitments and their effect on development theories. We have not given it any elaborate discussion here because it has been a subject of our research finding elsewhere. In the said work our contention was that what any society holds as true and the application of their sources of knowledge acquisition influence the rate of their development process. In the instance, we averred that the development success of Eurasia resulted from epistemic censorship they inherited from Judaism (See Chukwuokolo, 2007: pp. 10-20).

Again we have discussed materialism and development without discussing mind based theories of development; this will make our work unbalanced. This is also because we have discussed this elsewhere with daunting conclusion. Accordingly, we shall sum up this by asserting that though the mind actively plays fundamental roles in the course of development, it is hardly agreeable that it does so independent of the influence of the material conditions that surround its existence and operations. This does not mean that we subscribe to the materialistic thesis that confers passivity to the mind in the process of development. This means that presenting the self-its existence and relevance-in collective material transformations of social life, entails an end of an ontological mutism. This gravitates towards a convincing commitment to a materialist ontology of human subjectivity mingled with a humanist ontology of materialism. Thus seen, this envisions a dialectical unity between inter-subjectivity processes as grounding the processes of development. This brings out clearly the relevance of the traditionally mentalist constructs as the self as a fundamental mechanism for enhancing the participation of humans to social collaborative production of their lives. Thus, this expanded view does not merely call for the abrogation of dualism between individual and social process, rather it suggests ways of enhancing specific processes that make their dialectical unity possible. This stipulates what the self actually is, its location, its purposes and relation to society are. What's more? This con- 
ception brings out clearly the dialectical relations that exist among all important phases of qualified system of social life namely the general practice of material production, the social intercourse among people (dialogism of social life) and the self. Such agentive role of both individuals and social dimensions in human development is expanded thus making development a non reductive process (See Chukwuokolo, 2008: pp. 94-105).

It could be seen that the mind-based theorists of development aver that instead of emphasizing such external-materialists factors, premium should be placed on the spiritual dimension of man. Accordingly, development should emphasize such internal factors as values. Albert Schweitzer (1961) for instance posits that western civilization has reached its apogee in infrastructural development but is a disaster since it over-emphasizes materialist dimension of man. It is evident today that mankind is at the precipice of extinction via its break-throughs in science and technology. In the area of nuclear technology, man has manufactured arms of omnicide capacity. Mankind could be destroyed in a second if any of such nuclear arms is used. Albert Schweitzer (20) captures the implication of this when he asserts that western civilization is a disaster for "it is far more developed materially than spiritually; its balance is disturbed." However, it is noteworthy to acknowledge that over emphasis on the spiritual dimension of man is problematic as well. Our contention is that man should develop all his aspects-spiritual as well as material-equitably. This is what the clear directive role of philosophy should be in the formulation of development theories.

It follows therefore that since man is necessarily rational; anything focusing on man must necessarily focus on the development of his rationality. Thus seen, since philosophy is mankind's greatest exercise of rationality it follows that the application of rationality into development activities is the essential role of philosophy to development. It is worthy of note that the critical and evaluative role of philosophy to development spans to the kind of knowledge available to a people in the course of development. We have treated the epistemological import of knowledge base to development earlier. But suffice it to say that man's rational application of his intelligence influences the kind of knowledge base for him. This knowledge base in turn either accelerates or slows down the rate of development in any society. From the fore-going, it could be concluded that the import, roles and values of philosophy to development can never be over-emphasized.

We have seen so far that development theories have undergirding them some implicit perception of human nature. This holds the key to the understanding and application of such theories. Our contention is that for development theories to work effectively, the players must understand the need for the evaluation of the theories of human nature that spur such theo- ries and their suitability or otherwise for their value commitments. This is where ideological base of development theories are very relevant in the process of development. Societies should therefore formulate or accept development theories that they have evaluated their philosophical foundations. This will enhance the proper understanding and application of such theories. This is because theories are like architectural designs: unless one understands the design, one cannot build the house properly.

\section{REFERENCES}

Abel, R. (1976). Man is the measure. New York: The Free Press. Agbakoba, J. C. A. (2001). Theories of mind. Nsukka: University of Nigeria Press.

Agbakoba, J. C. A. (2003). Philosophical issues in development. Enugu: Fourth Dimension Publishers.

Berofsky, B. (1960). Freewill and determinism. New York: Harper and Row.

Braithwaite, R. (1968). Scientific explanation. Cambridge: Cambridge University Press.

Burlatsky, F. M. et al. (Eds.) (1985). The fundaments of Marxist*Leninist Philosophy. Moscow: Progress Publishers.

Chernyshevsky, N. G. (1950). The anthropological principle in philosophy. N. G. Chernyshevsky’s Works (Vol. 14). Moscow: Progress Publishers.

Chukwuokolo, J. C. (2007). A critical evaluation of the place of truth and knowledge in the process of development. Philosophy and Praxis Journal of the Nigerian Philosophical Association, 3, 10-20

Chukwuokolo, J. C. (2008). A critical examination of the impact of the mind-based theories for the development of the society. SWEM Journal of Religion and Philosophy Benue State University Markudi, 2, 94-105.

Hodgson, D. (1991). The mind matters. Oxford: Oxford University Press.

Hollis, M. (1977). Models of man. Cambridge: Cambridge University Press.

Kitchener, R. (1983). Development explanations. Review of Metaphysics, 36, 780-805

Lapati, A. (1973). Skinner and the nature of man. The New Scholasticism, 47, 501-502. doi:10.5840/newscholas19734747

Lenin, V. I. (1975). Collected works (Vol. 2). Moscow: Progress Publishers.

Marx, K. and Fredrick, E. (1976). Collected works (Vol. 21). Moscow: Progress Publishers.

Nagel, E. (1996). Determinism in History. In W. H. Dray (Ed.), Philosophical Analysis and History. New York: Harper and Row.

Omoregbe, J. I. (2004). Ethics a systematic and historical study. Lagos: Joja Press.

Ryan, A. (1975). The philosophy of the social sciences. London: Macmillan Press.

Schweitzer, A. (1961). Civilization and ethics. London: Unwin Books.

Stevensons, L. (1974). Seven theories of human nature. Oxford: Claredon Press.

Taylor, R. (1963). Metaphysics. Englewood Cliff: Prentice Hill Inc. 